\title{
The Integration of Social Emotional Learning and Cultural Education into Online Distance Learning Curricula: Now Imperative during the COVID-19 Pandemic
}

\author{
Neil F. Katzman1, Michael P. Stanton² \\ ${ }^{1}$ Harvard College, Cambridge, MA, USA \\ ${ }^{2}$ ECHO Institute, University of New Mexico, Albuquerque, MA, USA \\ Email: nkatzman@college.harvard.edu
}

How to cite this paper: Katzman, N. F., \& Stanton, M. P. (2020). The Integration of Social Emotional Learning and Cultural Education into Online Distance Learning Curricula: Now Imperative during the COVID-19 Pandemic. Creative Education, 11, 1561-1571. https://doi.org/10.4236/ce.2020.119114

Received: May 30, 2020

Accepted: August 30, 2020

Published: September 2, 2020

Copyright $\odot 2020$ by author(s) and Scientific Research Publishing Inc. This work is licensed under the Creative Commons Attribution International License (CC BY 4.0).

http://creativecommons.org/licenses/by/4.0/

\section{(c) (i) Open Access}

\begin{abstract}
The COVID-19 pandemic has demonstrated the importance of online distance education as a necessary platform for teaching learners at all levels both in the United States and throughout the world. The integration of social emotional learning and cultural education into online distance learning platforms has never been more critical to the success of future learners in society than during this time. This article addresses the current barriers to successful online learning including: 1) lack of secure broadband access in rural and underserved regions, 2) the importance of social emotional learning in online distance education, and 3 ) the critical need for cultural education within the online curricula of distance platforms.
\end{abstract}

\section{Keywords}

Distance Education, Social Emotional, Cultural Education, Project ECHO, COVID-19 Pandemic

\section{Introduction}

Technology has increased in classrooms across the world and many experts believe that this may create an even larger achievement gap (Cakir, et al., 2009, Joseph, 2009). As those with more wealth have access to broadband and the latest internet technologies, others less fortunate may not be able to close this educational divide. Many educational experts believe, however, that once barriers to broadband and internet accessible devices are reduced, technology has immense 
potential to decrease the achievement gap and democratize all levels of education (Bjerede \& Kruger, 2015; Hardesty et al., 2014). The demonopolizing of knowledge via online distance education for every student may provide an education that is equally enriching and empowering for all learners (Arora, et al., 2014). Social emotional learning (SEL), defined by The National Conference of State Legislators, "refers to a wide range of skills, attitudes, and behaviors that can affect a student's success in school and life. Critical thinking, managing emotions, working through conflicts, decision making, and teamwork are all skills not necessarily measured by tests, though they are crucial components of a student's education. These skills may impact his/her academic success, employability, self-esteem, relationships, as well as civic and community engagement" ("Social and Emotional Learning," 2018). "Online distance learning platforms" may be defined as "an integrated set of interactive online services that provides teachers, learners, parents and others involved in education with information, tools and resources to support and enhance educational delivery and management" ("What is a Learning Platform?," n.d.). Finally, "cultural education" may be described as "any form of education or teaching that incorporates the histories, texts, values, beliefs, and perspectives of people from different cultural backgrounds" (Partnership, 2013). An education that is rich in social emotional learning (SEL) and cultural sensitivity has the potential to be provided to all parts of the world, including under resourced and rural areas.

During the COVID-19 pandemic across the globe, many school systems have told teachers and learners to "stay at home". Prior to the pandemic, teachers might have acquired new educational information by talking informally to colleagues and administrators in-person at their schools and/or at educational conferences. These in-person gatherings, formal or informal, so cherished in the education system, have been virtually eliminated in the wake of the COVID-19 pandemic. To safely continue the educational process, most are turning to their internet devices for their sole source of standard educational material. A best practices implementation of SEL and cultural education into online distance platforms will be indispensable for the successful education of our next generation.

\section{Access to Technology for Successful Online Distance Education}

The creator of Khan Academy, Salman Khan, argues in his book The One World Schoolhouse: Education Reimagined, that education is at a "once in a millennium" transformational point (Khan, 2012). Khan believes that technology has the potential to transform the educational platform and make education accessible for all. "The Internet can make education far, far more accessible, so knowledge and opportunity can be more broadly and equitably shared" (Khan, 2012). Khan also elaborates on the idea of the "one world schoolhouse": "I composed a mission statement that was both wildly ambitious and-with the help of readily available but absurdly underutilized technology-ompletely attainable: Provide a free, world-class education for anyone, anywhere" (Khan, 2012). This idea of a "one world schoolhouse" that Khan argues for is the uto- 
pian-esque version of using technology to mitigate educational opportunities. Some educational experts fear that Khan academy cannot become a classroom replacement because of its lack of holistic teaching, including a neglect for SEL and cultural education (Phipps \& Kelly, 2016).

As Khan takes a positive view towards the future accessibility of technology in education, D. Jackson Maxwell emphasizes that there are still major social determinants of accessibility to technology for online learning to become a valid solution to the educational opportunity crisis (Maxwell, 2000). In "Technology and Inequality within the United States School Systems", D. Jackson Maxwell describes other factors that play into educational disparities in the United States (Maxwell, 2000). He describes three main "impediments" to accessing technology in the United States: gender bias, racial bias, and geographical location bias. Khan and Maxwell both agree that with access to equitable broadband and internet devices, technology can reduce educational disparities (Khan, 2012; Maxwell, 2000) to implement SEL and cultural education into online platforms, there must be access to online materials in the first place.

\section{Integrating Social Emotional Learning into Online Distance Education}

Once access to broadband and internet devices is obtained in the community, teachers then have the opportunity to create a best practice online environment for their learners. Many educational experts worry that distance education may increase a student's isolation. However, a best practice SEL curriculum implemented into distance learning platforms may help combat this fear for teachers. The fear is that isolation can lead to decreased accountability and engagement with the coursework in an online classroom environment. In fact, recent data from Harvard College supports this idea. The Undergraduate Council's Student Experience Survey examined student's experience with the transition from classroom to online learning in the Spring of 2020 secondary to the Covid-19 pandemic. Among other findings, undergraduates Jenny Gan and Oliver York found that "students reported that their overall emotional and physical health has declined. Nearly half of those surveyed reported that their physical health has worsened, and 81.1 percent of those surveyed reporting their emotional health has worsened." (Sharon Xu, Crimson Staff Writer, Harvard Crimson, "Harvard Students Report Strain of Online Semester in Undergrad Council Survey", 2020).

Han, Johnson, and Durlak et al., demonstrated the importance of SEL for learners' success both during and after school (Han \& Johnson, 2012; Durlak et al., 2011). In "Relationship between Students' Emotional Intelligence, Social Bond, and Interactions in Online Learning", Han and Johnson conducted a study to understand how emotional intelligence and behavior, such as the understanding of facial expressions, affect the social bond between peers and their behaviors in online classroom environments (Han \& Johnson, 2012). They found a positive correlation between students' emotional intelligence and their social bonds with peers in virtual environments (Han \& Johnson, 2012). If this 
argument is expanded to include SEL into the curriculum, a positive, beneficial cycle might be created between students raising their Emotional Intelligence levels, and their engagement with online learning. Peers connected with one another are likely to be more productive and more likely to continue online education, potentially raising their Emotional Intelligence levels even further (Han \& Johnson, 2012). Therefore, the implementation of SEL has the power to create better student outcomes by increasing not only student satisfaction and success, but also leading to greater longevity in online platforms (See Figure 1). This cycle has the power to reduce isolation, one of the main arguments against online distance learning. Durlak, et al. in their paper, "The Impact of Enhancing Students' Social and Emotional Learning: A Meta-Analysis of School-Based Universal Interventions" (Durlak et al., 2011) analyzed both the effectiveness of teaching SEL and the importance of SEL. The article found that "The [SEL curricula] also enhanced students' behavioral adjustment in the form of increased prosocial behaviors and reduced conduct and internalizing problems, as well as improved academic performance on achievement tests and grades" (Durlak et al., 2011). The authors use a metanalysis to support the same conclusion that Han and Johnson found: SEL curricula increases social behavior, whether in the traditional classroom setting or within online distance learning platforms (Durlak et al., 2011). The authors used the acronym SAFE (Sequences, Active, Focused and Explicit) to deduct if past studies had been applying SEL curricula into their research methods (Durlak et al., 2011).

Social emotional learning is often considered one of the main advantages over a traditional in person classroom setting. With the introduction of a SEL curricula into online learning platforms learners will not only have improved emotional

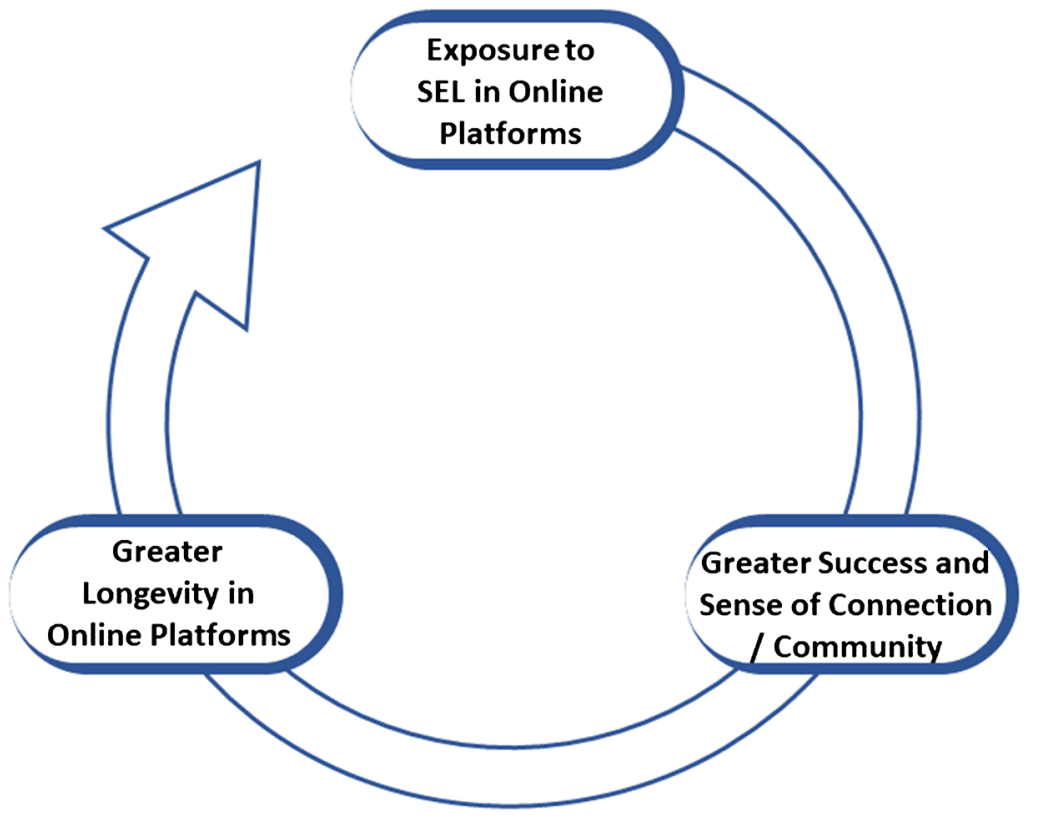

Figure 1. Cyclical Pattern of Better Student Outcomes through an Implementation of SEL Curricula. 
skills but will also be more likely to succeed in the online learning environment. This social emotional education will allow distance online education to compete with traditional schooling environments and mitigate educational opportunity disparities through improved online experiences.

\section{Integrating Cultural Education into Online Distance Education}

In addition to SEL, the integration of cultural education is critical to all students' success in online distance education platforms, In fact, there is a significant risk to educational success when online courses are taught without respect for the cultural sensitivity of their students. In most online distance education platforms, students are taught by teachers who know very little about the student's cultural background, nor social emotional world. Some educators have described the lack of cultural sensitivity as akin to a "cultural genocide" as it explains the critical importance of teacher-student understanding (Luke, 2009, Sheer, 2015, Wang \& Reeves, 2007).

The importance of cultural education in schools across the United States has been discussed by many in education, including Gloria Ladson-Billings. She describes cultural education using the term "culturally responsive teaching" in her book The Dreamkeepers, Successful Teachers of African American Children. Ladson-Billings describes culturally responsive teaching as "a pedagogy that empowers students intellectually, socially, emotionally, and politically by using cultural references to impart knowledge, skills, and attitudes" (Ladson-Billings, 1994). Billings believes that cultural education is imperative to a student's success in and out of the classroom and, that without this kind of teaching, a student may fail to understand his or her own culture. She argues that there is risk for a "cultural genocide" if culturally responsive teaching in not practiced within online distance platforms. To mitigate this risk, online learning platforms must move away from a "one size fits all" curricula and move to include specific cultural education pertinent to the target audience.

Supporting the critical importance of cultural literacy in online learning in their published works, Katharine Venter and Sultan Alalshaikh, describe that people of different cultures have vastly different experiences while completing online distance education. In their respective articles, "Coping with Isolation: The Role of Culture in Adult Distance Learners' Use of Surrogates."(Venter, 2003) and "Cultural Impacts on Distance Learning, Online Learning Styles, and Design" (Alalshaikh, 2015). These two authors come from distinct backgrounds and different parts of the world; however, they both come to the same conclusion. Katharine Venter argues that people across cultures experience feelings of isolation during online distance learning in dramatically different ways (Venter, 2003). Venter found that online learners experience social isolation in varied ways, as a result of their cultural differences (Venter, 2003). Online students from Asian Pacific countries tend to experience isolation during distance learning as isolation from teachers (Venter, 2003), while European learners tend to experience isolation relative to their peer relationships (Venter, 2003). Both 
Venter and Alalshaikh agree that the current online "one size fits all" model is not effective because learners who come from different environments have disparate experiences while completing online distance education. Thus, online distance learning platforms need to include educators who are culturally literate to the background of their students to ensure an optimal learning environment for the student.

\section{The Curricula in Cultural Education}

Cultural education can be deleterious if it is not taught from the lens of the students for whom the material is being created. Morong and DesBiens, highlight the need for cultural specific education (Morong \& Desbiens, 2016). In their article, "Culturally responsive online design: learning at intercultural intersection", they highlight the need for educational indigenization, putting the educational systems into the hands of the local groups as crucial for improved educational outcomes (Morong \& Desbiens, 2016). Morong and DesBiens argue in their proposed learning model the need for "a higher education system that respects (students) for who they are, that is relevant to their view of the world, that offers reciprocity in their relationships with others, and that helps them exercise responsibility over their own lives' by critical analysis of power relations" (Morong \& Desbiens, 2016). Morong and DesBiens believe that indigenization will allow for better understanding of the culture than using broad lines that would likely get drawn through online learning monopolies (Morong \& Desbiens, 2016). One of their main arguments is the imperative use of group work and collaboration to improve cultural education. This collaboration model is the perfect blend of SEL, interaction and improved and deepened cultural education and cultural sensitivity.

\section{New Mexico: A Case Example}

An example where great caution is needed regarding effective distance education is the state of New Mexico (NM). Largely rural and with only two million in population, New Mexico is the $5^{\text {th }}$ largest state, and ranks $49^{\text {th }}$ in the country for education ("Quality Counts 2018: Report and Rankings", 2020). Although NM has high rates of poverty, economic disparities, and unemployment, the cultures in NM are rich and vibrant (Kamerick, 2016). The ethnic composition of NM is diverse, with Hispanic, Caucasian and Native American comprising most of the population, which also includes over 30 distinct Native American pueblos as well as a large portion of the Navajo Nation (New Mexico Department of Health, 2019). Many elders in the Native American communities still use their own language. The Pueblo of Acoma, established in 1250 A.D. is the oldest inhabitable city in North America. For many remote NM counties, bandwidth is a constant barrier to internet use as well which impacts the success of online learning. The need for virtual SEL within the context of many cultural differences in New Mexico is even more crucial.

Broadband Barriers in New Mexico 
New Mexico has challenges with equitable access to the internet and internet accessible devices. Unless there is equal access to broadband across NM, school children and their teachers will not be able to utilize educational technologies, nor will culturally appropriate education be implemented with online distance platforms. Broadband access is lacking in many parts of the state, especially in tribal and very remote regions. Without access to internet capable devices, the benefit of educational opportunities using online platforms is not possible. These broadband technologies have the power to greatly diminish the widening education gap found in NM.

Once the barrier to broadband has been overcome and schools can acquire the technologies needed, social emotional learning in a culturally sensitive paradigm must be considered. New Mexico is an example of a state not only needing equitable access to online materials, but also requiring cultural sensitivity and SEL for successful distance education.

\section{The ECHO Institute, New Mexico's Project ECHO}

The ECHO Institute, in Albuquerque, NM, is the operations center for Project ECHO, a virtual synchronous telementoring program for post-licensure clinicians and educators (Arora, et al., 2011). Project ECHO began in 2003 as a mechanism to leverage technology and train primary care clinicians in rural and underserved communities. Clinicians at the "hub" site, the subject matter experts, train "spoke" clinicians using best practices didactics and real de-identified cases. Educators now also use Project ECHO to train teachers in remote settings regarding many aspects of education, including SEL, cultural competency and many other aspects important for the student's success. Currently, 49 US states have ECHO hubs for 70 different conditions in the fields of medicine, education and public health. Internationally, 39 countries have ECHO hubs with learners joining from over 150 countries.

ECHO for Education, for instance, recently, had 1842 educators from throughout NM participate in a series of workshops in April-May 2020 to address the school closure due to the COVID-19 pandemic. Its goal was to improve expertise and confidence in teachers providing online, virtual, and other non-traditional delivery methods of teaching necessary skills and standards to their students. Teachers were given assistance on many different online distance learning tools so they can more easily connect with their students in their virtual classrooms. Early workshops focused on certain technology tools and resources such as Google Classroom, using Zoom for virtual class meetings, and accessibility to online tools for all students in K-12. Based on the feedback received by nearly half of the ECHO webinar participants, the presentations focused on supporting students with special needs and offered resources to engage English Language Learners. In addition, implementation of SEL in online education was presented and discussed most frequently as a crucial topic for successful distance learning during the school closures from the pandemic.

Another Project ECHO example of SEL is the First Responder ECHO pro- 
gram, which began in August 2019. Given the extraordinarily high rates of post-traumatic stress disorder, compassion fatigue, vicarious trauma and suicide for first responders, this program began in order to reach first responders in a culturally sensitive manner (Katzman, Medrano, Swift, \& Menking, 2019). The "hub" team, which included a firefighter, a paramedic, a law enforcement officer, as well as a psychiatrist and emergency room physician was designed to best meet the needs of the NM First Responders. During the First Responder ECHO sessions, participants present real cases to the hub team, receive a best practice didactic and participate in a supportive community of practice. At times this has involved sharing emotions regarding difficult experiences in the field, and discussions about how to cope with these. This has led to mutual sharing of similar situations between participants online and the development of a supportive community.

In April 2020, the First Responder ECHO program, responding to the needs of all frontline clinicians due to the COVID-19 pandemic, expanded the interprofessional "hub" team to include: additional behavioral health clinicians, as well as pastoral care in order to provide guidance and social emotional support in a culturally sensitive approach. The name of the program became, First Responder Resiliency ECHO. The target audience still includes traditional first responders, but also is open to clinicians working in hospitals caring for COVID-19 patients. This may include: physicians, nurses, respiratory therapists, etc. The goal of this program is to bring together all frontline healthcare workers to support psychological health by focusing on the importance of self-care, resiliency, introducing psychological first aid and addressing the concepts of burn-out and compassion fatigue. Each session also includes breakout listening sessions facilitated by a hub team member. Between March 11, 2020 and June 11, 2020, participants attended eight sessions of the First Responder Resiliency Sessions for a total of 1764 attendances. In order for the participants to receive continuing education credit, the participants may elect (but are not required) to fill out a post-session survey. Eighty-seven percent of the participants who completed the survey stated that these sessions were relevant (4/5) or extremely relevant (5/5) on a 5-point Likert Scale.

\section{New Mexico's Schools: Online Applications}

Many education systems throughout NM, such as the Albuquerque Public School technology initiative, have expanded the use of technology in the classroom to help boost test scores and student outcomes ("Technology Vision \& Mission," n.d). Other digital solutions have come in the form of online "sessions" throughout the day on various online platforms, as well as the presence of "smart boards" throughout many classrooms. Other NM schools, including Zuni Elementary in Albuquerque, have moved to include "Digital Learning infusion throughout the curriculum" ("Project Based \& Technology Learning", n.d.) as well as using a web-based program called "Success Maker" ("Project Based \& Technology Learning", n.d.). 


\section{Conclusion}

As the COVID-19 pandemic continues to sweep across the globe, it is now more important than ever to increase the effectiveness of an online distance education. Social emotional learning and cultural components of an online distance platform must be implemented robustly and without compromise, but with knowledge and customization to the target audience. To summarize, a successful online education program will need to include: 1) stable access to internet and internet accessible devices throughout all regions of the globe, 2) effective SEL implemented into online distance platform curricula, 3) cultural education implemented in online distance learning consistent with the needs of learners.

Education is often called the great equalizer in any society, but often falls short of its mark. Given the significant geographic and socioeconomic disparities across the globe, technology has the opportunity to be a great equalizer. If broadband becomes equitable and online education is a reality for all, we must not forget the importance of integrating social emotional learning and cultural education into all forms of education.

\section{Conflicts of Interest}

The authors declare no conflicts of interest regarding the publication of this paper.

\section{References}

(2018). Social and Emotional Learning. National Conference of State Legislators. https://www.ncsl.org/research/education/social-emotional-learning.aspx

(2020). Quality Counts 2018: Report and Rankings. Education Weekly. https://www.edweek.org/ew/collections/quality-counts-2018-state-grades/index.html

(n.d.). Project Based \& Technology Learning. Albuquerque Public Schools. https://zes-aps-nm.schoolloop.com/magnet

(n.d.). Technology Vision \& Mission. Albuquerque Public Schools. http://www.aps.edu/technology/technology-vision-mission

(n.d.). What Is a Learning Platform? Timeless Learning Technology. http://www.timelwesslearntech.com/learning-platform.php

Alalshaikh, S. (2015). Cultural Impacts on Distance Learning, Online Learning Styles, and Design. Quarterly Review of Distance Education, 16, 67-75. https://eric.ed.gov/?id=EJ1143825

Arora, S., Kalishman, S., Dion, D., Som, D., Thornton, K., Bankhurst, A., Boyle, J., Harkins, M., Moseley, K., Murata, G., Komaramy, M., Katzman, J., Colleran, K., Deming, P., \& Yutzy, S. (2011). Partnering Urban Academic Medical Centers and Rural Primary Care Clinicians to Provide Complex Chronic Disease Care. Health Affairs (Project Hope), 30, 1176-1184. https://doi.org/10.1377/hlthaff.2011.0278

Arora, S., Thornton, K., Komaromy, M., Kalishman, S., Katzman, J., \& Duhigg, D. (2014). Demonopolizing Medical Knowledge. Academic Medicine, 89, 30-32. https://doi.org/10.1097/ACM.0000000000000051

Bjerede, M., \& Kruger, K. R. (2015). How Digital Equity Can Help Close the Homework Gap. The Journal: Technological Horizons in Education, 42, 6. 
Cakir, H., Deliakioglu, O., Dennis, A., \& Duggy, T. (2009). Technology Enhanced Learning Environments for Closing the Gap in Student Achievement between Regions: Does It Work? AACE Journal, 17, 45-47.

Durlak, J. A., Weissberg, R. P., Dymnicki, A. B., Taylor, R. D., \& Schellinger, K. B. (2011). The Impact of Enhancing Students' Social and Emotional Learning: A Meta-Analysis of School-Based Universal Interventions. Child Development, 82, 405-432. https://doi.org/10.1111/j.1467-8624.2010.01564.x

Grisham, M. (2018). A New Direction for New Mexico Schools.

Han, H., \& Johnson, S. D. (2012). Relationship between Students' Emotional Intelligence, Social Bond, and Interactions in Online Learning. Journal of Educational Technology \& Society, 15, 78-89.

Hardesty, J., McWilliams, J., \& Plucker, J. A. (2014). Excellence Gaps: What They Are, Why They Are Bad, and How Smart Contexts Can Address Them ... Or Make Them Worse, 2014. High Ability Studies, 25, 71-80. https://doi.org/10.1080/13598139.2014.907646

Harvard Crimson (2020). Harvard Students Report Strain of Online Semester in Undergrad Council Survey.

Hiltz, S. R., \& Turoff, M. (2005). Education Goes Digital. Communications of the ACM, 48, 59. https://doi.org/10.1145/1089107.1089139

Joseph, R. (2009). Closing the Achievement Gap with Culturally Relevant Technology-Based Learning Environments. Educational Technology, 49, 45-47.

Kamerick, M. (2016). New Mexico's Truth: Stunning Vistas and Child Poverty? NPR. https://www.npr.org/2016/04/04/472718935/new-mexicos-truth-stunning-vistas-and-c hild-poverty

Katzman, N., Medrano, J., Swift, R., \& Menking, P. (2019). First Responder Echo: Developing an Innovative Telementoring Program. Creative Education, 10, 1982-1987. https://doi.org/10.4236/ce.2019.109144

Khan, S. (2012). The One World Schoolhouse: Education Reimagined. Twelve.

Ladson-Billings, G. (1994). The Dream-Keepers: Successful Teachers of African American Children. San Francisco, CA: Jossey-Bass Publishers.

Luke, A. (2009). On Indigenous Education. Teaching Education, 20, 1-5. https://doi.org/10.1080/10476210902724011

Maxwell, D. (2000). Technology and Inequality within the United States School Systems. The Journal of Educational Thought, 34, 43-57. http://www.jstor.org/stable/23767141

Morong, G., \& Desbiens, D. (2016). Culturally Responsive Online Design: Learning at Intercultural Intersections. Intercultural Education, 27, 474-492.

https://doi.org/10.1080/14675986.2016.1240901

New Mexico Department of Health (2019). Health Indicator Report of New Mexico Population-Race/Ethnicity. New Mexico's Indicator-Based Information System. https://ibis.health.state.nm.us/indicator/complete profile/NMPopDemoRacEth.html

Partnership, G. S. (2013). Multicultural Education Definition. Education Glossary. http://www.edglossary.org/multicultural-education

Phipps, L., \& Kelly, B. (2016). Holistic Approaches to E-Learning Accessibility. Research in Learning Technology, 14, 69-78. https://doi.org/10.3402/rlt.v14i1.10939

Shear, S. (2015). Cultural Genocide Masked as Education: U.S. History Textbooks' Coverage of Indigenous Education Policies.

Venter, K. (2003). Coping with Isolation: The Role of Culture in Adult Distance Learners' 
Use of Surrogates. Open Learning, 18, 271.

https://doi.org/10.1080/0268051032000131035

Wang, C., \& Reeves, T. C. (2007). The Meaning of Culture in Online Education: Implications for Teaching, Learning and Design. In A. Edmundson (Ed.), Globalized E-Learning Cultural Challenges (pp. 1-17). Hershey, PA: IGI Global.

https://doi.org/10.4018/978-1-59904-301-2.ch001 